\title{
An Implicit Stereotype of the Rich and Its Relation to Psychological Connectedness
}

\author{
Chang-Jiang Liu, ${ }^{1,2}$ Yue Zhang, ${ }^{1}$ and Fang $\mathrm{Hao}^{1}$ \\ 1 School of Psychology, Nanjing Normal University, Nanjing, China \\ 2 Research Institute of Moral Education, Nanjing Normal University, Nanjing, China
}

\begin{abstract}
$\mathrm{T}$ his study investigates people's implicit stereotype of the social group of the rich in terms of competence and warmth. We further examine the stereotype's relationship with temporal selves. Implicit Association Tests were used as measures of implicit social perception in a social comparison context. We also rated the degree of psychological connectedness between current and possible future selves across time. Our results demonstrate that the rich are implicitly perceived as having high levels of competence and low levels of warmth compared to the average person, and that a close psychological connectedness mitigates the negative perception of the rich. The implications and limitations of these findings are also discussed.
\end{abstract}

Keywords: stereotype of the rich, Implicit Association Test, psychological connectedness, social perception

Social psychological research has previously demonstrated that social groups are stereotyped according to the characteristics of their social structure. Evidence has widely shown that people hold generally negative stereotypes about members of groups who are relatively disadvantaged, such as people with disabilities and those with low social status (Crocker \& Major, 1989). However, people also possess ambivalent stereotypes about advantaged groups, such as the rich and the powerful (Fiske, Cuddy, Glick, \& Xu, 2002). Moreover, previous research has shown that the explicit evaluations of social groups continue to bias social perceptions at an implicit level (Kunda \& Spencer, 2003). However, although implicit and explicit psychological processes correlate well on occasion, the two types of processes are often dissociated (Rudman, 2004).

Many social group attributes are automatically linked to the self. A social structure that is stereotypical of the social groups within that structure is characterised by status and power (Blader \& Chen, 2012). People will spontaneously seek a higher position within a social structure in order to satisfy their innate motivation of the desire for status, which in turn further affects their overall feelings of self-worth (Anderson, Hildreth, \& Howland, 2015). In addition, various social groups provide selfdefining goals to help facilitate the achievement of self over time (Gollwitzer \& Kirchhof, 1998). Since goals are an individual's ideal and aspired conception of themselves, individuals are more likely to expect themselves to become, for example, advantaged rather than disadvantaged. Therefore, one strategy that contributes favourably to the advantaged groups could be for members of the group to associate their current selves with their possible but desirable future selves. In this current study, taking the rich as a relatively advantaged group, we will demonstrate that the self in terms of temporal selves serves as a mechanism through which a general positive stereotype pertaining to the advantaged groups is implicitly formed.

\section{Social Perception of the Social Group of the Rich}

In general, people perceive the rich to possess meritorious qualities (Skafte, 1989). Also, people's feelings are generally favourable toward the rich (Shutts, Brey, Dornbusch, Slywotzky, \& Olson, 2016). Moreover, a positive perception of features or exemplars of the rich automatically develops into a 'global' impression. In this regard, the social group of the rich may be stereotyped as a desirable social category (Smith, DiTomaso, Farris, \& Cordero, 2001). More importantly, however, what has been demonstrated to date is that such a positive impression of ordinary people (regarding the rich) is based mainly on the features of the social success and personal development of exemplars. Both of these features are seen to define social competence (Christopher \& Jones, 2004; Horwitz, Shutts, \& Olson, 2014; Newheiser, Dunham, Merrill, Hoosain, \& Olson, 2014). In this manner, the rich are generally perceived as being similar to each other in terms of social competence. 
Previous research into stereotype content, however, has indicated that social cognition of the rich can differ in terms of social connections (Christopher \& Jones, 2004; Hogg et al., 2004). In existing social perception literature, social competence and connections are viewed as being the core and universal components of interpersonal and intergroup perceptions (Cuddy, Fiske, \& Glick, 2008; Fiske, Cuddy, \& Glick, 2007). Theoretically, this differentiation is captured in the so-called 'Big Two' of (1) competence (agency) and (2) warmth (morality/ communion; see Abele \& Wojciszke, 2013). The competence dimension refers to traits that are related to personal goal attainment, as well as the growth of individual traits, including intelligence, skill, creativity, and efficacy. By contrast, the warmth dimension is comprised of traits that are related to the formation and maintenance of social connections. These traits include friendliness, helpfulness, sincerity, trustworthiness, and morality (Abele \& Wojciszke, 2007; Fiske et al., 2002).

In the Big Two framework, the rich (which may include people with high incomes, the upper-class, and business people) are generally perceived as fitting into the category of high competence and low warmth (Fiske, 2012). On the one hand, people sensibly attach competence to those holding prestigious jobs and to those who are economically successful. On the other hand, the perception of low warmth may stem from the reality that the richer groups are targets for innumerable negative projections and derogatory labels. Consequently, the rich are perceived as being more selfish, cocky, and hypocritical. They are also seen as being less considerate of others than less affluent people are seen to be (Christopher \& Schlenker, 2000; Johannesen-Schmidt \& Eagly, 2002).

The above mixed or ambivalent perceptions might especially be true in the context of social comparison. People think of others in terms of prototypes (Anderson \& Sedikides, 1991). These prototypes are constructed as fuzzy sets of interrelated traits. Previous research has indicated that prototypes vary across situations as a function of the social comparison frame (Hogg et al., 2004). With changes in prototypes, the feelings toward and perceptions of the rich also vary. In addition, it has been previously demonstrated that ordinary people tend to treat the rich social group as an outgroup (Tajfel \& Turner, 1979; for a review, see Hewstone, Rubin, \& Willis, 2002). The result is ingroup favouritism and outgroup derogation. Thus, in reality, a negative representation of the rich lacking warmth, as opposed to an overall favouritism for the societal stereotyped groups, would be formed and extended to the outgroup.

\section{Psychological Connectedness of Temporal Selves}

According to Parfit (1971), the self is a collection of one's distinct identities that psychologically connect with one another over time. In general, people tend to view their possible future selves as favourable and desirable.
Therefore, people tend to prefer what they perceive to be their future selves, compared to their backward past selves. For instance, people perceive their future selves as being more attractive and positive. People also see themselves attending more to their future selves than to their current selves (Haddock, 2006; Stephan, Sedikides, Heller, \& Shidlovski, 2015; Van Boven \& Caruso, 2015). These people often form an expectation that they are living their lives on a continuous, upward trajectory (Busseri, Choma, \& Sadava, 2009; Loewenstein \& Prelec, 1993).

Despite being seen as being favourable and desirable, future selves are, at least to some extent, viewed and treated like other people (Ersner-Hershfield, Wimmer, \& Knutson, 2009; Pronin, 2008). Because an individual's continuity of memories, interests, and other characteristics diminish, the degree of psychological connectedness between the present and future selves generally tends to decrease over time (Frederick, 2003). Moreover, future selves incorporate broader and more superordinate identities than do present selves (Wakslak, Nussbaum, Liberman, \& Trope, 2008). In summary, future selves will frequently be treated as 'others' or outgroups. Additionally, people may not identify strongly with a more temporally distant future self (Wilson, Buehler, Lawford, Schmidt, \& Yong, 2012).

However, people also strive to improve themselves over time as they attempt to approach their desired and ideal future selves (Taylor, Neter, \& Wayment, 1995). The motivation behind this active self-improvement might depend on the individual's strength of psychological connectedness with their future selves, because the self has the ability to generate a feeling of temporal connectedness that integrates the present with the future (Kuhl, Quirin, \& Koole, 2015). A growing body of research has indicated that the perceived connectedness between the current and future selves is closely associated with how people think and behave in social interactions. For instance, when people are prompted to focus on their future selves, they are more likely to behave in ethically responsible ways (Hershfield, Cohen, \& Thompson, 2012). Efforts to increase the degree of connectedness to the future selves tend to lead to more farsighted and patient behaviour (Bartels \& Rips, 2010; Ersner-Hershfield, Garton, Ballard, Samanez-Larkin, \& Knutson, 2009). Evidence on self-other overlap also suggests that the inclusion of the other in the self has positive effects on social relationships. These positive effects include less stereotyping (Galinsky, Ku, \& Wang, 2005) and greater celebration of others' successes (Gardner, Gabriel, \& Hochschild, 2002). Therefore, identifying ways to increase the degree of connectedness between the current self and future selves (and thus the desirable others) may lead to more positive perceptions of and treatment of others.

\section{Current Study}

One aim of our current study was to demonstrate a mixed implicit stereotype of the rich. It has been suggested that 
self-report measures of social perception are biased, due to a limited insight into one's own motivational and cognitive processes and by other biases, such as social desirability (Fazio \& Olson, 2003). Conversely, implicit measures can assess automatic evaluations without a person's knowledge of what is being assessed (Hahn, Judd, Hirsh, \& Blair, 2014). Implicit measures are, therefore, verified as more objective means of measuring social perception.

In this study, Implicit Association Tests (IATs; Greenwald, McGhee, \& Schwartz, 1998) were conducted to assess the implicit effects toward the rich. In the IATs, respondents were asked to categorise stimuli into one of four superordinate categories, representing two concept dimensions. The first dimension is social groups: the rich versus the average person. The second dimension is preferences: positive versus negative. In this regard, the IAT serves as a comparative measure of implicit effects that assesses the evaluative associations of one group relative to another. The coexistence of two opposing groups thus sets a social comparison situation where an individual's social connections become salient.

Evidence has shown that people exhibit an implicit favourability toward the rich, even though they explicitly resent the rich and powerful, even to the point of taking revenge against them (Zhou \& Wang, 2007). However, research into stereotype content suggests that a mixed implicit stereotype may exist. More specifically, the perceived discrepancy of perception between the real group and its desirable prototypes may lie in the warmth component rather than the competence component. In contrast to an overall favorable impression and consistent with social perceptions of the Big Two framework, the following hypotheses are proposed:

H1a: Exemplars of the rich will be associated more quickly and easily with the high than the low competence component.

H1b: Exemplars of the rich will be associated more quickly and easily with the low than the high warmth component.

Another aim of the current study was to investigate the relationships of the implicit perception of the rich with the psychological connectedness between different temporal selves. According to social identity theory (Tajfel \& Turner, 1979), the disadvantaged strive to achieve a positive social identity. They do this, for example, by leaving or dissociating themselves from the ingroup. According to the selfcompletion theory (Gollwitzer \& Kirchhof, 1998), once people have set themselves certain identity goals, they will, over a long period of time, respond to failure experiences, shortcomings or barriers with intensified efforts to reach their goals. Since positive perceptions of the rich tend to motivate people to approach their desired future selves, the average person has an inner motivation to accumulate possessions and wealth and thus become a member of the rich group. In this way, individuals may share a common identity with the rich. They may even see themselves as having qualified to be members of the rich group. Therefore, people's representations of the rich may denote a prospective form of their future selves. It is this prospective form that may further guide their current behaviours toward wealth accumulation. For instance, imagining a future state of being wealthy could lead individuals to take high risks with their personal outcomes (Greenberg, 2013).

We hereby propose that an implicit positive stereotype of the rich will be achieved, or strengthened, by increasing the psychological connectedness between the current self and the temporally distant future self (i.e., the identity of the advantaged). That is, an increase in psychological connectedness between the current self and the desirable future self is predicted to mitigate the low warmth stereotype of the rich and to elevate the high competence stereotype of the rich. We therefore hypothesise that:

H2a: Stronger psychological connectedness will be positively related to a higher level of the current implicit perception of the high competence of the rich.

H2b: Stronger psychological connectedness will be negatively related to a higher level of the current implicit perception of the low warmth of the rich.

\section{Methods}

\section{Participants and Design}

A total of 124 undergraduate students were recruited from the campus of a large public university. All participants were right-handed and had normal or corrected-tonormal vision. Data from 15 participants were discarded because of excessive errors in the implicit measures (in excess of $20 \%$ of the trials). Ultimately, the valid data consisted of those from 34 males and 75 females, whose ages ranged from 18 to 23 , with an average of $20.35(S D=1.44)$.

\section{Materials}

IATs. The main tasks performed in this study were two IATs; specifically, warmth and competence IATs. First, the target and attribute categories were identified, along with the corresponding stimuli used in the IATs. In general, both IATs had two target category labels, 'the rich' versus 'the average person'. Both IATs also had two attribute category labels, 'negative' versus 'positive. The target stimuli were nouns categorised as the rich or the average person, while the attribute stimuli were adjectives that represented warmth or competence.

Target category stimuli were selected through the following procedures: First, the authors gathered to brainstorm words that represented the rich and the average people in society. A total of 20 nouns were chosen to categorise the rich person, and 15 nouns were chosen to categorise the average person. Second, six graduate students were asked to rank the top 10 words for each category during a graduate seminar. Finally, based on the rankings, the eight 
most frequently occurring words from each category were selected as experimental stimuli (see Appendix).

Attribute category stimuli were obtained through a similar three-step procedure, as follows: First, the stimuli validated in previous research (Abele, Uchronski, Suitner, \& Wojciszke, 2008; Bruckmüller \& Abele, 2013; Fiske et al., 2007 ) were collected. This procedure generated a total of 109 adjectives, including 24 words representing positive warmth, 35 for negative warmth, 29 for positive competence, and 21 for negative competence. Subsequently, the words were translated into Chinese. Second, the six graduate students were asked to rank the top 15 words in their respective categories during the same seminar at which they ranked the target category stimuli. Finally, based on the ranks, the eight most frequently occurring words in each of the four categories were included as experimental stimuli (see Appendix).

Following the recommendation made by Greenwald, Nosek, and Banaji (2003), each IAT was administered in seven blocks. Three (specifically, the first two and the fifth) were practice blocks (20 trials each) that were used to acquaint participants with the categorisation rules. The remaining blocks were the critical test blocks. For both of the IATs, the third and fourth blocks (which included 20 and 40 trials respectively) were compatible tasks. Compatibility in the IATs refers to the positive implicit stereotype of competence and the negative implicit stereotype of warmth (with regard to the rich). Therefore, the participants in the warmth IAT were asked to press the left-hand response key ' $\mathrm{E}$ ' if the stimulus was either 'the rich' or 'negative warm word' and the right-hand response key 'I' if the stimulus was 'the average person' or 'positive warm words'.

The sixth and seventh blocks (which included 20 and 40 trials, respectively) were incompatible tasks. Incompatibility in the IATs corresponded to a negative implicit stereotype of competence and a positive implicit stereotype of warmth toward the rich. Therefore, the pairings in these blocks were reversed, whereby the stimuli related to 'the rich' and 'positive warm words' shared a single response key 'E', while the stimuli related to 'the average person' and 'negative warm words' shared the other single response key 'I'.

The competence IAT was similar to the warmth IAT, except that the labels of 'negative' and 'positive' in the latter were replaced with 'positive' and 'negative', respectively, in the former. Moreover, the attribute stimuli of 'warmth' words were replaced by those of 'competence' words.

Prior to each IAT block, instructions regarding the sorting task operations and the appropriate key responses were presented on the screen. During each trial, the stimuli appeared in the centre of the screen, while the four category reminder labels were appropriately positioned on the right and left at the top of the screen. The participants responded to the request to categorise stimuli to the left and right groups quickly and with minimal errors. The response times and error rates of each test trial were recorded automatically. Each incorrect response was identified by a red X centred below the stimulus for 200 $\mathrm{ms}$. Each incorrect response was then corrected before the next stimulus was presented.

\section{Measure of Psychological Connectedness}

Following the example of Frederick's (2003) operationalisation, the degree of psychological connectedness between the current and desirable future selves across time was assessed, based on the degree of similarity between the self and the target of the rich. For comparison purposes, psychological connectedness between the current and another type of possible future selves was also assessed, based on the degree of similarity between the self and the target of the average person. A total of 12 items ( 6 for each target group) were included. The items for each target group differed across six different time periods. Those time periods included 0 (meaning current time), 5, 10, 20, 30, and 40 years. Participants were asked to rate their similarity with the target group on a scale ranging from 0 (representing no similarity) to 100 (indicating complete similarity). Sample items included 'How similar are you to the rich people now?' and 'How similar will you be to the average person 30 years from now?' Participants were initially required to consider characteristics such as personality, temperament, likes and dislikes, beliefs, values, ambitions, goals, and ideals.

\section{Procedures}

Upon arriving at the lab, the participants were seated before a computer monitor on which the stimuli were presented. The participants were randomly assigned to either a competence IAT or a warmth IAT. Thereafter, they were instructed to complete their respective tests. To eliminate any possible sequence and association effects, half of the participants were first given the warmth IAT, followed by the competence IAT. That sequence was reversed for the other half of the participants. In addition, odd-numbered participants were presented with one stage of the IAT and then the other. That order was reversed for even-numbered participants.

Each IAT lasted approximately 10 minutes. Thereafter, the participants reported their similarities to the rich and to the average person via a 100-point sliding scale. Then their demographic characteristics were collected. Finally, participants were thanked and debriefed. Each of them was paid 5 yuan (approximately US $\$ 0.80$ ) for their participation.

\section{Results}

\section{Implicit Stereotype of the Rich}

The IAT effects for implicit stereotypes pertaining to the rich were conventionally computed separately (for the competence and warmth IATs). This was done by subtracting the mean latency for the compatible task from the mean latency for the incompatible task. Among the 
Table 1

Average Response Times and D Scores of the Two IATs

\begin{tabular}{llrl}
\hline & \multicolumn{2}{c}{ Response times } & \\
\cline { 2 - 3 } Dimension & Compatible task & Incompatible task & \multirow{2}{*}{ D scores } \\
\hline Competence & $880.99(239.25)$ & $1088.20(286.31)$ & $0.45(0.45)$ \\
Warmth & $942.77(228.67)$ & $995.98(262.19)$ & $0.10(0.41)$ \\
\hline
\end{tabular}

Note: $S D$ s in parentheses.

more common methods of computing this difference, the $D$ scores were selected, because the $D$-scoring algorithm can powerfully assess the relationships between implicit effects and other variables of interest (Greenwald et al., 2003). In this method, high $D$ scores indicated an implicit perception of high competence and low warmth toward the rich. Table 1 presents the average response times and $D$ scores in the compatible and incompatible tasks.

The results of the pairwise $t$ tests (for the competence IAT) showed that the response time in the compatible task was much shorter than the response time in the incompatible task, $t(53)=-6.42, p<.001$. Thus, the response time was accelerated when the 'rich' words were paired with the positive 'competence' words relative to negative ones. A one-sample $t$ test showed that the mean $D$ score of 0.45 was significantly greater than zero, $t(53)=7.40$, $p<.001$. In addition, $85.2 \%$ of the participants had a $D$ score of greater than zero. Collectively, these findings suggest a significant implicit effect of high competence. Thus, H1a is fully supported.

The response time in the incompatible task for the warmth IAT was shorter than the response time in the compatible task, $t(54)=-1.96, p=.056$. Thus, the response time was accelerated when the 'rich' words were paired with negative 'warmth' words, relative to positive ones. A one-sample $t$ test on the mean $D$ score of 0.10 indicated that participants from the warmth group exhibited a negative implicit preference of warmth to the rich, $t(54)=1.87, p=.066$. In addition, $60 \%$ of the participants had a $D$ score greater than zero. Collectively, these findings suggest a marginally significant implicit effect of low warmth. Thus, $\mathrm{H} 1 \mathrm{~b}$ is also supported at only marginal levels of significance.

\section{Correlations Between Implicit Stereotype and Self-Other Similarity}

Table 2 presents the descriptive statistics of the self-other similarities over time. Perceived similarities between the self and the rich gradually increased from 31.80 to 69.82 for the warmth group and from 34.50 to 65.65 for the competence group across the six defined life periods. On the other hand, perceived similarities between the self and the average person decreased from 79.45 to 58.51 for the warmth group, and from 71.06 to 55.46 for the competence group. Indeed, using the linear-by-linear association chisquare test, a significant association for each trend over the defined time periods was documented at the .05 level.

\section{Table 2}

Descriptive Statistics Of Self-Others Similarities Over Time In Both Groups

\begin{tabular}{llllll}
\hline & \multicolumn{2}{c}{$\begin{array}{c}\text { Similarity between the } \\
\text { self and the rich }\end{array}$} & & \multicolumn{2}{c}{$\begin{array}{c}\text { Similarity between the } \\
\text { self and the average person }\end{array}$} \\
\cline { 2 - 3 } \cline { 5 - 6 } & Warmth & Competence & & Warmth & Competence \\
\hline Item 1 & $31.80(22.49)$ & $34.50(22.52)$ & & $79.45(21.48)$ & $71.06(24.13)$ \\
Item 2 & $48.35(18.30)$ & $48.93(20.83)$ & & $71.55(21.38)$ & $67.26(25.33)$ \\
Item 3 & $57.45(17.84)$ & $57.20(21.52)$ & & $67.02(22.70)$ & $63.04(25.01)$ \\
Item 4 & $65.36(18.27)$ & $62.76(22.20)$ & $61.58(25.70)$ & $58.96(25.24)$ \\
Item 5 & $68.76(19.96)$ & $65.04(23.69)$ & $60.58(27.65)$ & $55.46(29.06)$ \\
Item 6 & $69.82(20.27)$ & $65.65(24.17)$ & & $58.51(27.28)$ & $55.81(29.37)$ \\
M-H $\chi^{2}$ & $4.43^{*}$ & $4.28^{*}$ & & $4.62^{*}$ & $4.76^{*}$ \\
\hline
\end{tabular}

Note: For each similarity, items differed from 1 to 6 in time periods that ranged from 0 (the current time) to 40 years with an increasing time trend. SDs in parentheses.

$\mathrm{M}-\mathrm{H} \chi^{2}=$ Mantel-Haenszel chi-square for linear-by-linear trends

$* p<.05$.

\section{Table 3}

Correlations Between Implicit Stereotypes and Self-Others Similarity

\begin{tabular}{cccc}
\hline & & $\begin{array}{c}\text { Competence } \\
\text { D scores }\end{array}$ & $\begin{array}{c}\text { Warmth } \\
D \text { scores }\end{array}$ \\
\hline Similarity between the self & Item 1 & -.01 & $-.39^{* *}$ \\
and the rich & Item 2 & -.04 & $-.41^{* *}$ \\
& Item 3 & -.10 & $-.39^{* *}$ \\
& Item 4 & -.11 & $-.34^{*}$ \\
& Item 5 & -.15 & $-.30^{*}$ \\
Similarity between the self & Item 6 & -.14 & $-.30^{*}$ \\
and the average person & Item 1 & -.12 & .19 \\
& Item 2 & -.02 & .18 \\
& Item 3 & .07 & .18 \\
& Item 4 & .08 & .06 \\
& Item 5 & .15 & .10 \\
\hline
\end{tabular}

Note: For each similarity, items differed from 1 to 6 in time periods that ranged from 0 (the current time) to 40 years with an increasing time trend.

${ }^{*} p<.05,{ }^{* *} p<.01$

Thus, our results confirm that people tend to associate increasing and decreasing trends of similarity with the rich and the average respectively over time.

Table 3 presents the correlation coefficients between the $D$ scores and the similarities between the self and the rich. As shown, the correlation coefficients between the competence $D$ scores and the similarities between the self and the rich decreased gradually across the six selected life periods, from -0.01 to -0.15 . This result indicates an increased relationship between an implicit stereotype of the rich and psychological connectedness across a lifetime. In other words, for near future selves, almost no correlation exists between how much people see this self as being like the rich and their current views about the competence of the rich. However, for distant future selves, it appears that the more people view that self as being like the rich, the less they view the rich as being stereotypically competent. However, none of these correlations differed significantly from zero. Thus, H2a was not confirmed by our test results.

The correlation coefficients between the warmth $D$ scores and the similarities between the self and the rich were all significant at the .05 level. Moreover, the 
coefficients increased across the six selected life periods from -.41 to -.30. In addition, a linear-by-linear association chi-square test showed a significant association between the coefficients over time periods at the .05 level, indicating that the more people see themselves becoming like the rich as they age, the weaker becomes the correlation with their current implicit warmth perception of the rich. In other words, for near future selves, the more people see themselves as being like the rich, the less they currently view the rich as being stereotypically cold. However, this relationship becomes slightly weaker for more distant selves. That is to say, the more people view their distant self as being like the rich, the more inclined they are to currently see the rich as being stereotypically cold.

For all participants, all six items related to similarities between the self and the rich correlated significantly with one another. Cronbach's alpha for these items was .93. Therefore, the scores for the items were combined in order to generate a composite score of mean similarity between the self and the rich. The correlation coefficient between this mean and the warmth $D$ score was $-0.43, p<.01$. Furthermore, the regression result of this $D$ score (with the mean similarity between the self and the rich as the predictor) indicates that similarity significantly predicts people's implicit perceptions of the rich as being warm and moral, $F=12.08, p=.001, R^{2}=.43$. Thus, $\mathrm{H} 2 \mathrm{~b}$ is supported.

In addition, the correlation coefficients between the competence $D$ scores and the similarities between the self and the average person increased gradually across the six selected life periods, from -.12 to .23 . Conversely, the correlation coefficients between the warmth $D$ scores and these similarities decreased from .19 to .06 . However, none of these correlations reached any degree of statistical significance.

\section{Discussion}

The research presented in this article investigated the implicit social perceptions of ordinary people toward the social group of the rich. Our study also sought to find the role of self in social perception. Grounded within the Big Two framework (Abele \& Wojciszke, 2013; Cuddy et al., 2009; Holoien \& Fiske, 2013), an implicit ambivalent association was observed in a social comparison context. That is, the participants demonstrated a negative implicit stereotype in terms of warmth rather than competence when the social group of the rich was compared with the social group comprised of average persons. As is consistent with the predictions found in self-related theories, this association was related to the degree of strength of the psychological connectedness between different temporal selves.

The mixed implicit stereotype of high competence and low warmth held by the average person toward the rich was verified in our study. In reality, the rich generate wealth and prosperity for society, leading the average person to consider that they themselves possess the ability to achieve self-worth. However, the rich tend to exhibit a significantly low level of social connections and thus find themselves frequently being criticised (Cheng, 2009; Dittmar, 1992; Dworkin, 1996; Fiske \& Cuddy, 2006). Theoretically, it has been argued that competence is desirable for oneself, whereas warmth is desirable for others. In addition, judgments of competence and warmth stem from perceived socio-economic status and perceived interdependence respectively (Cuddy, Fiske, \& Glick, 2008). Thus, the evaluation of competence is an intrapersonal process and independent of social connections. Conversely, the evaluation of warmth follows from the perceived relationship of the group to social perceivers. Consequently, this type of difference in the social structural roots of the judgments of both warmth and competence intensifies the degree of the ambivalent perception of both dimensions in relation to the rich.

Moreover, evidence from previous studies demonstrates that with regard to social information processing, warmth is preferred over competence, both in the sense that warmth is judged before competence and that judgments of warmth carry significant weight in affective and behavioural reactions (Abele \& Bruckmüller, 2011; Bruckmüller \& Abele, 2013; Wojciszke, 2005). As with these processing asymmetries, negative information tends to influence individual evaluations more strongly than does positive information (Peeters \& Czapinski, 1990; Vaish, Grossmann, \& Woodward, 2008). Therefore, the processing asymmetries of warmth and competence may also contribute to the formation of the real-life ambivalent perceptions of the rich.

Most importantly, our results demonstrate a relationship between the self and the perception of social groups. People normally strengthen and accumulate wealth over time, the process of which ultimately manifests in these people becoming the rich. In this way, as our results have demonstrated, people tend to define their future selves as being more similar to the rich than to an average person. This perceived similarity (and thus the enhanced degree of psychological connectedness) between the current and future selves increases the attraction toward the target group (Montoya, Horton, \& Kirchner, 2008). Our results show that people who see themselves as being more like the rich tend to currently perceive the rich as being less cold. However, these same people do not currently perceive the rich as being more competent. Actually, they even view them as being less competent, albeit not to any significant degree. According to the self-completion theory (Gollwitzer \& Kirchhof, 1998), if ordinary people see themselves as being more like (or even likely to become) the rich, their positive identity achievement should not then damage their sense of self-integrity or self-esteem. Thus, reducing the negative evaluations of the self (i.e., being cold) can protect or maintain one's self-esteem. However, an increased degree of similarity between the self and the rich may make salient the lack of one's current competence. 
This may slightly damage ordinary people's confidence when attempting to pursue a positive identity. However, of course, as noted above, this damaged confidence does not lead ordinary people to currently perceive the rich as being less competent to any significant extent. People still maintain an overall favourable impression of the rich in terms of social competence.

Moreover, our results show that increasing the distance in time can significantly weaken the strength of the relationship between the self and the warmth perception of the rich. Evidence shows that people represent and construe their distant-future selves in a simpler and more decontextualised fashion than they do with their near-future selves (Trope \& Liberman, 2010; Wakslak et al., 2008). In this way their distant-future selves (e.g., identity of the rich) are actually perceived as belonging to a global but abstract social category. This type of category then leads people who see themselves as being more like the rich to no longer currently perceive the rich as being that warm.

The present findings have implications for applied issues. Given the current implicit perception of low degrees of warmth, the rich should improve their social connections and their concerns regarding overall social welfare more than the level currently perceived by the group comprised of ordinary people. For instance, the charitable contributions from the richest Chinese constitute only a small proportion of the total donations (Piff, Kraus, Côté, Cheng, \& Keltner, 2010; Tipton, 2012). However, these individuals do donate large amounts to charity. The rich should understand that giving to charities will actually benefit them more over the long term than will taking from society (Dunn, Aknin, \& Norton, 2014; Grant, 2013).

An increasing degree of connectedness between the current self and the future self is related to the stereotype of high warmth toward the rich. However, a caveat is that people may accept the current negative sides of their future selves in order to maintain a consistent identity. For example, corruption is a problem in all countries and generally threatens economic growth. If normal citizens discover that the rich have obtained their wealth through some improper means, they (the normal citizens) may become more willing and inclined to participate in corruption (Č́belková \& Hanousek, 2004). If people identify their future self as a member of the rich group, they may tolerate or even accept crimes committed by the rich. The normal citizens will do so because they hold onto the motivations of self-esteem and self-consistency to maintain a self-concept (Rosenberg, 1979; Steele, 1988). In this manner and in this respect, people have the potential to become corrupt.

The research presented in this article is not without limitations. First, only marginally significant implicit effects of low warmth stereotype were observed. This finding weakens our argument. However, even the statistically small effects of the implicit test can still be seen to have great societal significance (Greenwald, Banaji, \& Nosek, 2015). For instance, repeated exposure to negative events and news regarding the rich indeed strengthens people's inner belief that the rich generally lack warmth and morality and that they only care to maintain their own power and competence. Second, the nature of the impression of the social group of the rich may be blended with that of possessing wealth. When the concept of the rich is mentioned, symbols of wealth and possession are automatically activated and vice versa. However, these symbols differ in that the features attached to the social group of the rich are more social in nature. These symbols are thus more informative than those attached to an object of wealth. For example, people may care about and anticipate that one should return something to society once she or he becomes wealthy. However, wealth itself does not guarantee this type of reciprocity. Third, our current analyses are correlational in nature. They do not imply causal directions. Although our theoretical analyses on positive identity achievement support the role of the self in stereotypes of the advantaged, other possible explanations may still exist. For example, people who currently think less negatively about the warmth of the rich will be more likely to see themselves as becoming like the rich as they get older. Future studies should clarify this issue.

\section{Concluding Remarks}

The Big Two framework of social perception reflects two basic dimensions of warmth and competence in social judgment. On the other hand, theories pertaining to the self and identity imply that individuals strive to achieve distinct positive selves across time. This article supports the notion that social perceptions of the advantaged are automatically associated with high degrees of competence and low degrees of warmth in the comparison context. However, because of positive identity achievement, increased psychological connectedness of the current self to future self (stereotyped as an ideal representation of the rich) would mitigate the negative perception of warmth toward the rich. Therefore, those who are already rich should improve their social connections, particularly in terms of warmth, in order to maintain an overall favourable social image. Those who strive for wealth and prosperity should cultivate their social connections and engage themselves in social welfare activities and improvements. The warmth dimension of social perception would automatically become active once such individuals become rich. This would, in turn and in the long run, facilitate the achievement of social harmony.

\section{Acknowledgments}

We would like to thank the editor and two anonymous reviewers for their valuable comments and constructive suggestions.

\section{Funding}

This research is supported by the key research center funding of Humanities and Social Science of Ministry of 
Education China (Grant No. 16JJD880026) and a grant from the National Natural Science Foundation of China (Grant No. 71690242).

\section{Appendix}

List of attribute words and target words used in the IATs

\begin{tabular}{|c|c|c|c|}
\hline \multicolumn{4}{|c|}{ Attribute Words of Warmth } \\
\hline & \multicolumn{2}{|c|}{ Negative } \\
\hline Chinese & English & Chinese & English \\
\hline 友好的 & Friendly & 无情的 & Hard-hearted \\
\hline 乐于助人的 & Helpful & 虚伪的 & Hypocritical \\
\hline 热心的 & Warm-hearted & 自私自利的 & Egoistic \\
\hline 真诚的 & Sincere & 奸诈的 & Insidious \\
\hline 诚实的 & Honest & 卑鄙的 & Mean \\
\hline 合作的 & Cooperative & 专横的 & Dominating \\
\hline 宽容的 & Tolerant & 敌视的 & Unfriendly \\
\hline 有爱心的 & Caring & 不负责任的 & Irresponsible \\
\hline
\end{tabular}

Attribute Words of Competence

\begin{tabular}{|c|c|c|c|}
\hline \multicolumn{2}{|c|}{ Positive } & \multicolumn{2}{|c|}{ Negative } \\
\hline Chinese & English & Chinese & English \\
\hline 有能力的 & Able & 缺乏自律的 & $\begin{array}{l}\text { Lacking self- } \\
\text { discipline }\end{array}$ \\
\hline 有主见的 & Strong-minded & 懒散的 & Lazy \\
\hline 善于思考的 & Meditative & 消极被动的 & Passive \\
\hline 有创造力的 & Imaginative & 平庸的 & Incapable \\
\hline 自信的 & Self-confident & 肤浅的 & Unknowing \\
\hline 独立自主的 & Independent & 愚笨的 & Stupid \\
\hline 敏锐的 & Discriminating & 缺乏条理的 & Unorganized \\
\hline 聪明的 & Clever & 优柔寡断的 & Waving \\
\hline \multicolumn{4}{|l|}{ Target words } \\
\hline \multicolumn{2}{|c|}{ The Rich } & \multicolumn{2}{|c|}{ The Average Person } \\
\hline Chinese & English & Chinese & English \\
\hline 富豪 & Billionaire & 一般人 & The average man \\
\hline 大款 & Tycoon & 平常人 & Mediocrity \\
\hline 富有的人 & The affluent & 老百姓 & Rank and File \\
\hline 有钱人 & The wealthy & 平民 & Civilian \\
\hline 富翁 & Moneybags & 大众 & The Public \\
\hline 富婆 & Wealthy woman & 平凡人 & Ordinary People \\
\hline 富二代 & $\begin{array}{l}\text { Rich Second } \\
\text { Generation }\end{array}$ & 群众 & Crowd \\
\hline 土豪 & Parvenu & 民众 & The Populace \\
\hline
\end{tabular}

Note: IATs $=$ Implicit Association Tests.

\section{References}

Abele, A.E., \& Bruckmüller, S. (2011). The bigger one of the 'Big Two'? Preferential processing of communal information. Journal of Experimental Social Psychology, 47, 935-948.

Abele, A.E., \& Wojciszke, B. (2007). Agency and communion from the perspective of self versus others. Journal of Personality and Social Psychology, 93, 751-763.
Abele, A.E., \& Wojciszke, B. (2013). The Big Two in social judgment and behavior. Social Psychology, 44, 61-62.

Abele, A.E., Uchronski, M., Suitner, C., \& Wojciszke, B. (2008). Towards an operationalization of the fundamental dimensions of agency and communion: Trait content ratings in five countries considering valence and frequency of word occurrence. European Journal of Social Psychology, 38, 1202-1217.

Anderson, C., Hildreth, J.A.D., \& Howland, L. (2015). Is the desire for status a fundamental human motive? A review of the empirical literature. Psychological Bulletin, 141, 574-601.

Anderson, C.A., \& Sedikides, C. (1991). Thinking about people: Contributions of a typological alternative to associationistic and dimensional models of person perception. Journal of Personality and Social Psychology, 60, 203-217.

Bartels, D.M., \& Rips, L.J. (2010). Psychological connectedness and intertemporal choice. Journal of Experimental Psychology: General, 139, 49-69.

Blader, S.L., \& Chen, Y.R. (2012). Differentiating the effects of status and power: A justice perspective. Journal of Personality and Social Psychology, 102, 994-1014.

Bruckmüller, S., \& Abele, A.E. (2013). The density of the Big Two: How are agency and communion structurally represented? Social Psychology, 44, 63-74.

Busseri, M.A., Choma, B.L., \& Sadava, S.W. (2009). 'As good as it gets' or 'The best is yet to come'? How optimists and pessimists view their past, present, and anticipated future life satisfaction. Personality and Individual Differences, 47, 352-356.

Čábelková, I., \& Hanousek, J. (2004). The power of negative thinking: Corruption, perception and willingness to bribe in Ukraine. Applied Economics, 36, 383-397.

Cheng, B.-Q. (2009). From envy to resentment: On a side of emotional atmosphere in Chinese society. Exploration and Free Views, 10, 49-52.

Christopher, A.N., \& Jones, J.R. (2004). Affluence cues and first impressions: The moderating impact of the Protestant work ethic. Journal of Economic Psychology, 25, 279-292.

Christopher, A.N., \& Schlenker, B.R. (2000). The impact of perceived material wealth and perceiver personality on first impressions. Journal of Economic Psychology, 21, 1-19.

Crocker, J., \& Major, B. (1989). Social stigma and self-esteem: The self-protective properties of stigma. Psychological Review, 96, 608-630.

Cuddy, A.J., Fiske, S.T., \& Glick, P. (2008). Warmth and competence as universal dimensions of social perception: The stereotype content model and the BIAS map. Advances in Experimental Social Psychology, 40, 61-149.

Cuddy, A.J., Fiske, S.T., Kwan, V.S., Glick, P., Demoulin, S., Leyens, J.P., ... Ziegler, R. (2009). Stereotype content model across cultures: Towards universal similarities and some differences. British Journal of Social Psychology, 48, 1-33.

Dittmar, H. (1992). Perceived material wealth and first impressions. British Journal of Social Psychology, 31, 379-391.

Dunn, E.W., Aknin, L.B., \& Norton, M.I. (2014). Prosocial spending and happiness using money to benefit others pays off. Current Directions in Psychological Science, 23, 41-47. 
Dworkin, R.W. (1996). The rise of the imperial self: America's culture wars in Augustinian perspective. Lanham, MD: Rowman \& Littlefield.

Ersner-Hershfield, H., Garton, M.T., Ballard, K., SamanezLarkin, G.R., \& Knutson, B. (2009). Don't stop thinking about tomorrow: Individual differences in future self-continuity account for saving. Judgment and Decision Making, 4, 280-286.

Ersner-Hershfield, H., Wimmer, G.E., \& Knutson, B. (2009). Saving for the future self: Neural measures of future selfcontinuity predict temporal discounting. Social Cognitive and Affective Neuroscience, 4, 85-92.

Fazio, R.H., \& Olson, M.A. (2003). Implicit measures in social cognition research: Their meaning and use. Annual Review of Psychology, 54, 297-327.

Fiske, S.T. (2012). Warmth and competence: Stereotype content issues for clinicians and researchers. Canadian Psychology/Psychologie Canadienne, 53, 14-20.

Fiske, S.T., \& Cuddy, A.J.C. (2006). Stereotype content and relative group status across cultures. In S. Guimond (Ed.), Social comparison processes and levels of analysis: Understanding culture, intergroup relations and cognition (pp. 249-263). Cambridge, UK: Cambridge University Press.

Fiske, S.T., Cuddy, A.J.C., \& Glick, P. (2007). Universal dimensions of social cognition: Warmth and competence. Trends in Cognitive Sciences, 11, 77-83.

Fiske, S.T., Cuddy, A.J., Glick, P., \& Xu, J. (2002). A model of (often mixed) stereotype content: Competence and warmth respectively follow from perceived status and competition. Journal of Personality and Social Psychology, 82, 878-902.

Frederick, S. (2003). Time preference and personal identity. In G. Loewenstein, D. Read, \& R. Baumeister (Eds.), Time and decision (pp. 89-113). New York, NY: Russell Sage Foundation.

Galinsky, A.D., Ku, G., \& Wang, C.S. (2005). Perspective-taking and self-other overlap: Fostering social bonds and facilitating social coordination. Group Processes and Intergroup Relations, 8, 109-124.

Gardner, W.L., Gabriel, S., \& Hochschild, L. (2002). When you and I are 'we,' you are not threatening: The role of selfexpansion in social comparison. Journal of Personality and Social Psychology, 82, 239-251.

Gollwitzer, P.M., \& Kirchhof, O. (1998). The willful pursuit of identity. In J. Heckhausen \& C.S. Dweck (Eds.), Motivation and self-regulation across the life span (pp. 389-423). New York, NY: Cambridge University Press.

Grant, A. (2013). Give and take: A revolutionary approach to success. London: Hachette UK.

Greenberg, A.E. (2013). When imagining future wealth influences risky decision making. Judgment and Decision Making, $8,268-277$.

Greenwald, A.G., Banaji, M.R., \& Nosek, B.A. (2015). Statistically small effects of the Implicit Association Test can have societally large effects. Journal of Personality and Social Psychology, 108, 553-561.
Greenwald, A.G., McGhee, D.E., \& Schwartz, J.L. (1998). Measuring individual differences in implicit cognition: The implicit association test. Journal of Personality and Social Psychology, $74,1464-1480$.

Greenwald, A.G., Nosek, B.A., \& Banaji, M.R. (2003). Understanding and using the implicit association test: I. An improved scoring algorithm. Journal of Personality and Social Psychology, 85, 197-216.

Haddock, G. (2006). Do I get better looking each day? Changes in self-perceptions of attractiveness as a function of temporal perspective. European Journal of Social Psychology, 36, 761-771.

Hahn, A., Judd, C.M., Hirsh, H.K., \& Blair, I.V. (2014). Awareness of implicit attitudes. Journal of Experimental Psychology: General, 143, 1369-1392.

Hershfield, H.E., Cohen, T.R., \& Thompson, L. (2012). Short horizons and tempting situations: Lack of continuity to our future selves leads to unethical decision making and behavior. Organizational Behavior and Human Decision Processes, 117, 298-310.

Hewstone, M., Rubin, M., \& Willis, H. (2002). Intergroup bias. Annual Review of Psychology, 53, 575-604.

Hogg, M.A., Abrams, D., Otten, S., \& Hinkle, S. (2004). The social identity perspective intergroup relations, selfconception, and small groups. Small Group Research, 35, 246-276.

Holoien, D.S., \& Fiske, S.T. (2013). Downplaying positive impressions: Compensation between warmth and competence in impression management. Journal of Experimental Social Psychology, 49, 33-41.

Horwitz, S.R., Shutts, K., \& Olson, K.R. (2014). Social class differences produce social group preferences. Developmental Science, 17, 991-1002.

Johannesen-Schmidt, M.C., \& Eagly, A.H. (2002). Diminishing returns: The effects of income on the content of stereotypes of wage earners. Personality and Social Psychology Bulletin, 28, 1538-1545.

Kuhl, J., Quirin, M., \& Koole, S.L. (2015). Being someone: The integrated self as a neuropsychological system. Social and Personality Psychology Compass, 9, 115-132.

Kunda, Z., \& Spencer, S.J. (2003). When do stereotypes come to mind and when do they color judgment? A goal-based theoretical framework for stereotype activation and application. Psychological Bulletin, 129, 522-544.

Loewenstein, G.F., \& Prelec, D. (1993). Preferences for sequences of outcomes. Psychological Review, 100, 91-108.

Montoya, R.M., Horton, R.S., \& Kirchner, J. (2008). Is actual similarity necessary for attraction? A meta-analysis of actual and perceived similarity. Journal of Social and Personal Relationships, 25, 889-922.

Newheiser, A.K., Dunham, Y., Merrill, A., Hoosain, L., \& Olson, K.R. (2014). Preference for high status predicts implicit outgroup bias among children from low-status groups. Developmental Psychology, 50, 1081-1090.

Parfit, D. (1971). Personal identity. The Philosophical Review, 80, 3-27. 
Peeters, G., \& Czapinski, J. (1990). Positive-negative asymmetry in evaluations: The distinction between affective and informational negativity effects. European Review of Social Psychology, 1, 33-60.

Piff, P.K., Kraus, M.W., Côté, S., Cheng, B.H., \& Keltner, D. (2010). Having less, giving more: The influence of social class on prosocial behavior. Journal of Personality and Social Psychology, 99, 771-784.

Pronin, E. (2008). How we see ourselves and how we see others. Science, 320, 1177-1180.

Rosenberg, M. (1979). Conceiving the self. Malabar, FL: Krieger Publishing.

Rudman, L.A. (2004). Sources of implicit attitudes. Current Directions in Psychological Science, 13, 79-82.

Shutts, K., Brey, E.L., Dornbusch, L.A., Slywotzky, N., \& Olson, K.R. (2016). Children use wealth cues to evaluate others. PloS One, 11, e0149360.

Skafte, D. (1989). The effect of perceived wealth and poverty on adolescents' character judgments. Journal of Social Psychology, 129, 93-99.

Smith, D.R., DiTomaso, N., Farris, G.F., \& Cordero, R. (2001). Favoritism, bias, and error in performance ratings of scientists and engineers: The effects of power, status, and numbers. Sex Roles, 45, 337-358.

Steele, C.M. (1988). The psychology of self-affirmation: Sustaining the integrity of the self. In L. Berkowitz (Ed.), Advances in experimental social psychology (vol. 21, pp. 261-302). San Diego, CA: Academic Press.

Stephan, E., Sedikides, C., Heller, D., \& Shidlovski, D. (2015). My fair future self: The role of temporal distance and selfenhancement in prediction. Social Cognition, 33, 149-168.

Tajfel, H., \& Turner, J.C. (1979). An integrative theory of intergroup conflict. In W.G. Austin \& S. Worchel (Eds.), The social psychology of intergroup relations (pp. 33-47). Monterey, CA: Brooks/Cole.

Taylor, S.E., Neter, E., \& Wayment, H.A. (1995). Self-evaluation processes. Personality and Social Psychology Bulletin, 21, $1278-1287$.

Tipton, B.A. (2012). Follow the money: Philanthropy in China - Who's giving, to whom, and why? (Unpublished Masters thesis). The University of British Columbia, Vancouver, Canada.

Trope, Y., \& Liberman, N. (2010). Construal-level theory of psychological distance. Psychological Review, 117, 440-463.

Vaish, A., Grossmann, T., \& Woodward, A. (2008). Not all emotions are created equal: The negativity bias in social-emotional development. Psychological Bulletin, 134, 383-403.

Van Boven, L., \& Caruso, E.M. (2015). The tripartite foundations of temporal psychological distance: Metaphors, ecology, and teleology. Social and Personality Psychology Compass, 9, 593-605.

Wakslak, C.J., Nussbaum, S., Liberman, N., \& Trope, Y. (2008). Representations of the self in the near and distant future. Journal of Personality and Social Psychology, 95, 757-773.

Wilson, A.E., Buehler, R., Lawford, H., Schmidt, C., \& Yong, A.G. (2012). Basking in projected glory: The role of subjective temporal distance in future self-appraisal. European Journal of Social Psychology, 42, 342-353.

Wojciszke, B. (2005). Morality and competence in person- and self-perception. European Review of Social Psychology, 16, $155-188$.

Zhou, F., \& Wang, D. (2007). Dissociation between implicit and explicit attitudes towards the rich in a developing country: The case of China. Social Behavior and Personality, 35, 295-302. 